\title{
Information System for the Management of Off- Grid Renewable Energy Systems for Decentralized Consumers
}

\author{
Irina Usacheva* \\ Volgograd State University, Institute of Economics and Management, 400064 Volgograd, Russian \\ Federation
}

\begin{abstract}
The paper studies technical features of managing off-grid renewable energy systems; analyses principles of building a resourceprocess model of energy supply for a local facility with several energy sources; shows a conceptual scheme of the proposed direct current microgrid; develops a database structure of automated control system of offgrid energy systems in SQL.
\end{abstract}

\section{Introduction}

Centralized and non-renewable systems, namely large-scale facilities using fossil fuels such as oil and coke, are environmentally unsustainable because they rely on resource depletion. Furthermore, these exhaustible resources result in high greenhouse gas emissions (CO2 emissions) from several processes during their life cycle that contributes to global warming [1-3]. As a result, they lead to other pollution problems during their extraction and transport processes.

Renewable and distributed resources such as small solar and wind generators are more environmentally sustainable because they use local and renewable energy sources, resulting in lower environmental impacts than the various fossil fuel extraction, conversion and distribution processes. They also have much lower greenhouse gas emissions. Compared to centralized systems, on-site energy production and distribution improve reliability and reduce distribution losses [4].

The main advantage of distributed renewable energy (DRE) systems relates to their reliability and resilience. In fact, due to their distributed architecture, DRE systems can easily cope with individual failures due to the capacity of each energy-consuming node being served by several energy production units. By contrast, a breakdown in a centralized system may affect the distribution of energy throughout the system. For example, small generating units for energy production are operated by small economic entities, where the user can be an example (producer + consumer), and generating units can connect to a micro-energy network, potentially linked to the global grid [5,6]. From this perspective, DRE systems can facilitate the democratization of energy access, thereby contributing to reducing inequality, self-

\footnotetext{
* Corresponding author: zeppelin89@volsu.ru
} 
reliance and self-governance. There is evidence that distributed renewable energy can provide energy access to more than 1 billion people by 2025 .

\section{Materials and methods}

One important area of research is developing a comprehensive approach to the selection of parameters for energy installations with a wide range of unconventional and renewable energy sources and an information system for determining the technically and economically optimal energy source.

The development of a renewable energy off-grid management system for decentralized energy systems has benefited from various research methods. A cyclic method of interrogating sources of information allowed gathering information about the continuously changing parameters of the control object. Conversion of the voltage (current) value into a digital code involves the following methods: sweep conversion without feedback; sweep conversion with feedback; and per-digit equalization. The information system was created in C\# using MSSQL Server.

\section{Results and discussion}

\subsection{Transition to decentralized and distributed energy systems}

The transition from centralized to decentralized and distributed energy systems needs to consider the following elements:

-structure of the system relating to the configuration of the actors involved in the energy system;

-types of energy sources depending on the nature of the resources, from non-renewable to renewable energy sources [7].

As regards the structure of the system, it is possible to distinguish between the following three main types: centralized, decentralized and distributed.

We can define centralized energy systems as large unit energy production systems that provide energy through an extensive distribution network, often far from the point of use [8].

We can define decentralized energy systems as small power units (facilities) that supply energy to local consumers [9]. These production units may be off-grid or may be linked to other nearby units through a network to share resources, i.e. to share surplus energy [10-12]. In the latter case, they become locally decentralized energy networks, which may, in turn, interconnect with a number of similar networks.

It is possible to define a distributed energy system as a small unit energy production system, at or near the place of use, where users are producers: whether individuals, small businesses and/or local communities [13]. These production units may be off-grid or may be linked to other neighbouring businesses through a network to share resources, i.e. to share surplus energy. In the latter case, they become locally decentralized energy networks, which may, in turn, interconnect with nearby similar networks.

\subsection{Modelling of hybrid generation}

Optimal selection of conversion equipment is necessary to meet the requirements of the load [14]. There are a number of useful modelling and optimization techniques to assess the performance of hybrid wind energy systems. Commonly used software tools include Hybrid Optimization Model for Renewable Energy (HOMER), HYBRID2, Hybrid Optimization with GA (HOGA), HYBRIDS, Hydrogen Energy Models (HYDROGEMS), Transient 
Systems Simulation Software (TRNSYS), Village Energy Optimization for Renewables (ViPOR), Dymola and the Matrix Laboratory Simulink Toolbox (MATLAB) used for cost and performance analysis. These optimization tools have helped to optimize the simulation configuration in terms of production costs and reliability.

An off-grid hybrid system consists of a hybrid energy storage device (battery and supercapacitor), a relief load and a mains load to obtain voltage and frequency regulation. Figure 1 shows the energy management algorithm.

Energy parameters of the energy supply system (generation schedule, specific energy cost of the i-th source, capacity of sources during peak load periods, storage capacity, technical condition of sources, etc.)

Control actions (advisory messages), energy management, monitoring budget utilization, creating templates (optimization scenarios) matching demand with UDT based on energy management strategy

Fig. 1. Principles for building a resource-process model for the energy supply of a local facility with multiple energy sources.

Consequently, ensuring the balance between the load and the generation source requires efficient and intelligent software. To achieve this, it is possible to predict the load demand and plan the regulated capacity [15]. Depending on the power flow, we can distinguish three categories: centralized control, distributed control and hybrid control. With centralized control, the system consists of one master controller (centralized controller) and several slave controllers for the various individual power supplies and energy storage. The master controller works in close coordination with all sources and slave controllers.

In a distributed control system, each power supply sends measurement signals to its local controller. The local controllers communicate with each other to make the appropriate decision for the global optimum solution. A hybrid control scheme is a combination of centralized and distributed control schemes. In a hybrid management scheme, RESs are grouped into a single system [16]. Each group uses a centralized management scheme, and a distributed management scheme coordinates each group [17]. Such a hybrid control scheme allows achieving local optimization through centralized control within a group, while distributed control provides global optimization among the different groups of energy sources.

The research work identified the main and basic requirements for the system. The main requirement is that the system can operate at all times of the year and at all times of the day. Consequently, it needs to provide a certain amount of batteries for a normal and uninterrupted power supply [18]. This is also important when selecting a built-in unit, as it must also have a long period of continuous operation. It should also provide information on energy consumption and production, and output of predicted data.

These requirements result in identifying the following system functionalities 
1. Energy generation and storage

1.1. Production using alternative energy sources

1.2. Energy storage in battery equipment

2. Energy data collection

2.1. Energy production data collection.

2.2. Energy consumption data collection.

2.3. Energy purchase data collection.

3. Prediction of data

3.1. Prediction of future energy consumption

3.2. Prediction of future energy production

3.3. Calculation of the optimal purchase quantity.

4. Output of data to the user.

4.1. Output of energy consumption data

4.2. Output of energy production data

4.3. Output of the predicted data

We then worked out the architecture of the system (Figure 2).

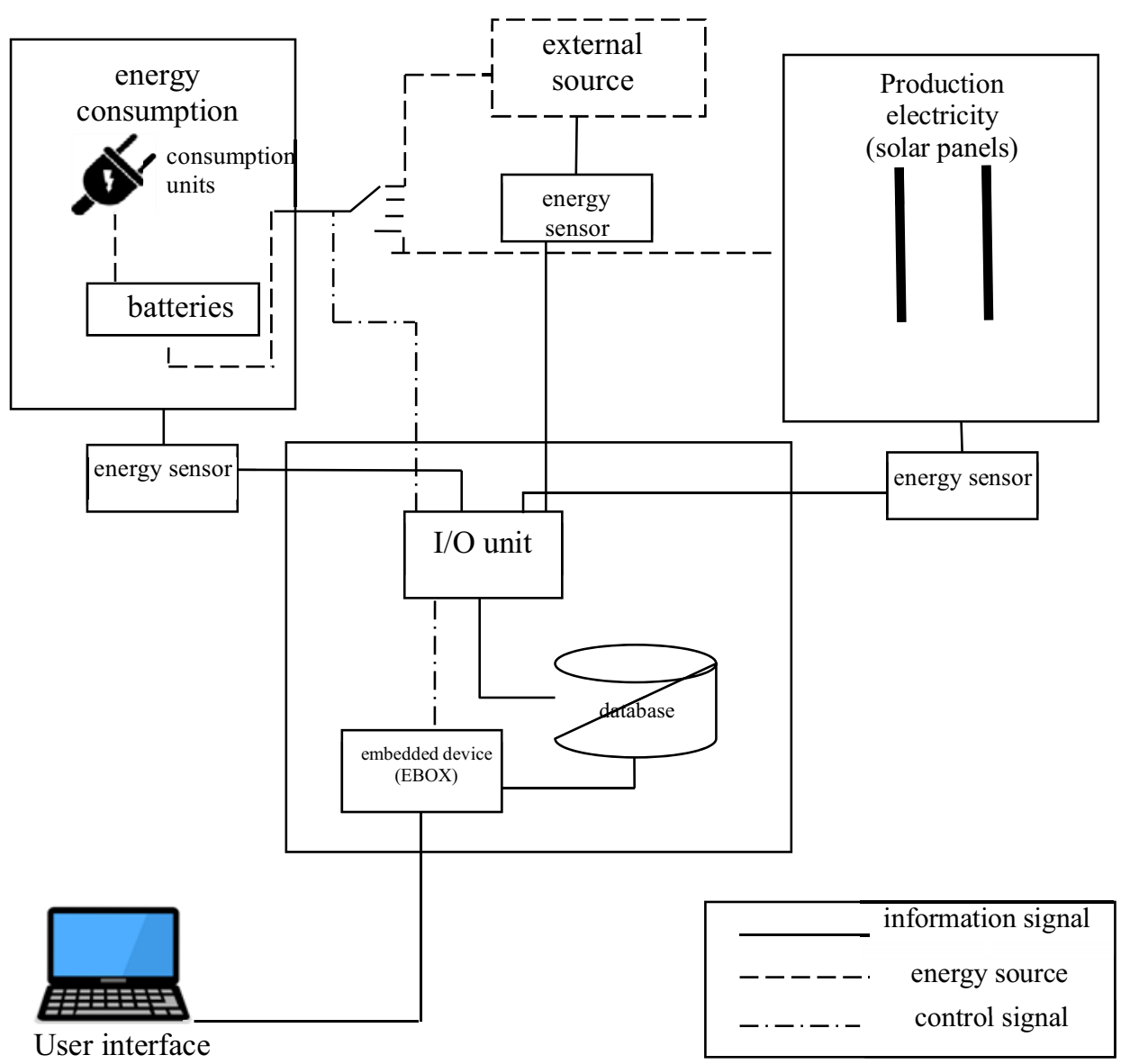

Fig. 2. Architecture of the system.

Figure 2 shows that the system has 3 types of system component interaction lines. The power generation, consumption unit and the external source send the information signals through the I/O unit, where they take a digital form and then move on to the database for 
output to the user and subsequent analysis (prediction). Data analysis and prediction takes place in an embedded device. The latter is ebox recommended by Microsoft as an embedded solution. Since it has no moving components, it features a wide operating temperature and humidity range. It is also relatively inexpensive.

Depending on the calculations made, the embedded device sends a control signal to the $\mathrm{I} / \mathrm{O}$ unit, which in turn sends a control relay to switch between the energy sources.

The Adam 6051 will serve as the output device, as it is compatible with the largest number of energy sensors. The solar panels and batteries can be of any kind, depending on the customer's paying capacity and monthly energy consumption. The Emis Electra 975 was selected as the sensor because it has different settings for tariff control. Any Pentium 4 or higher computer can function as a Database Server.

The programme was created in C\# using MSSQL Server. We made this choice due to the software that will be transferred to the embedded device when ported to the Windows Embedded CE 6.0 R3 format. To display the prediction information on the client side, we implemented a web application that receives and sends requests to the software via the soap web service. Data provided by Porta Capena served as a test sample.

The cross-platform SQLite embedded database, which supports a fairly complete set of SQL commands and is available in source code, is chosen as the information storage system (Figure 3).
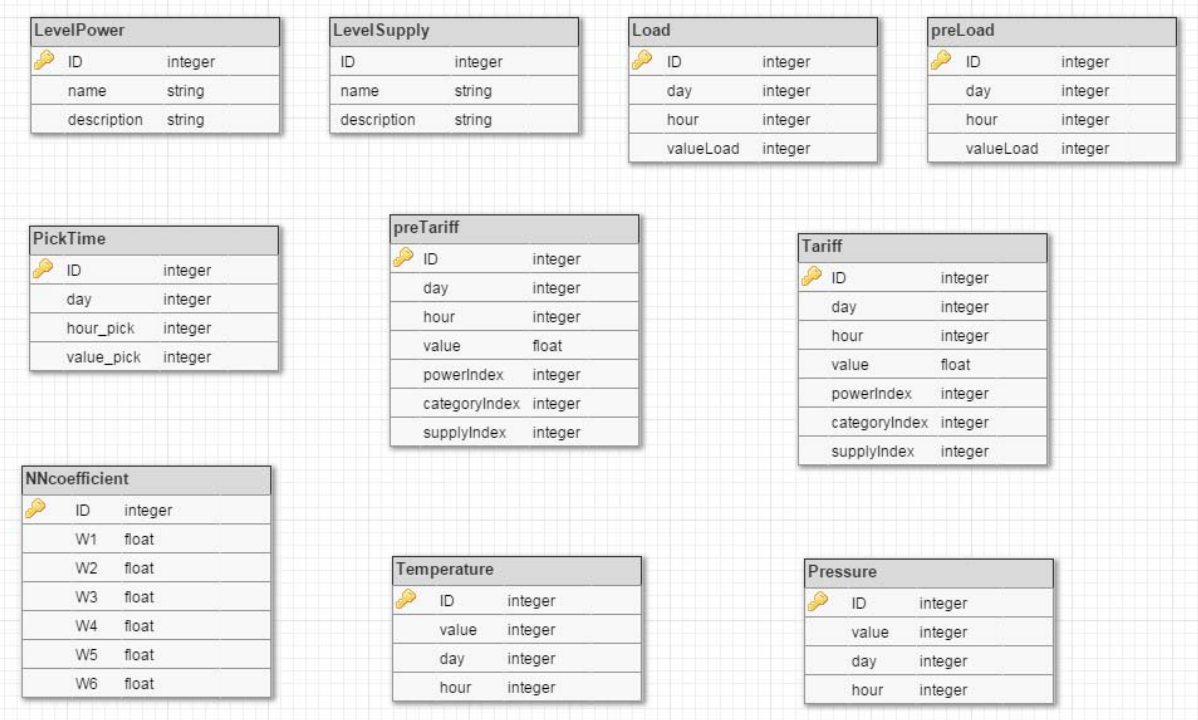

Fig.3. System database structure in SQL notation.

The system allows the search for optimum shares of installed capacity for each type of equipment for a specific area using statistical data (wind speed, insolation, temperature parameters).

\section{Conclusion}

The paper presents a variant of building a multilevel automatic control system of RES-based electricity generation complex for decentralized consumers, providing possibilities of transition of operational, dispatch and process control of energy power systems from 
monitoring of current mode to proactive control methods with anticipation of events and timely initiation of changes.

The study was carried out with the financial support of Grant of the President of the Russian Federation (project No. MK-1362.2020.9).

\section{References}

1. R. Hunter, and G. Elliot, Un.of Cam. (1994)

2. R. Sternberger, D. Jovcic, IEEE Trans. on Pow.Del. 23, 4 (2008)

3. V. Elistratov, I. Kudryasheva, P. Pilipets, Applied Mechanics and Materials Energy efficient solutions of power supply in north regions 725-726, 1463-70 (2015)

4. GG Oggier, GO Garca, and AR Oliva, IEEE Trans. on Pow.Del., 24, 7 (2009)

5. S. Ben-Yaakov, " IEEE Trans. on Ind.El., 59, 1. (2012)

6. L. Schwager, A. Tuysuz, C. Zwyssig, JW Kolar, IEEE Trans. on In. Appl., 50, 2, (2014)

7. H. H. Yang, V. Zhou, and C. Z. Lu, Appl. Ener., 86, 2 (2009)

8. Usacheva, E. Gladkaya, Sh. Khurshudyan, CSSDRE 2019, 83 (2019)

9. V. Elistratov, Ren. Ener. (2016)

10. L. Ponomareva, I. Usacheva, A. Volkova., Lec. No. in Netw. and Syst., 155 (2021)

11. S. S. Reddy, B. K. Panigrahi, R. Kundu, R. Mukherjee, S. Debchowdhury, Int.J. of El. Pow. and Pow. Syst., 53, 1 (2013)

12. M. Starovoytov, E. Popkova, E. Gladkaya. Contr.to Econ, 9783319454610 (2017)

A. A. Khatir, R. Cherkaoui, Stud. of El. Pow. Sys., 81, 4 (2011)

13. A.K. Shukla, K. Sudhakar, P. Baredar, Ener. Buil., 140 (2017)

14. K.S.P.B. Mary Debbarma, Ren. Sust. Ener. Rev, 73 (2017)

15. X. Zhang, J. Shen, Y. Lu, W. He, P. Xu, X. Zhao, et al., Ren. Sust. Ener. Rev, 50 (2015)

16. S. Poppi, N. Sommerfeldt, C. Bales, H. Madani, P. Lundqvist, Ren. Sust. Ener. Rev, 81 (2018)

17. E. O'Shaughnessy, D. Cutler, K. Ardani, R. Margolis, Appl. Ener., 213 (2018)

18. G. Alva, Y. Lin, G. Fang, Ener., 144 (2018) 